
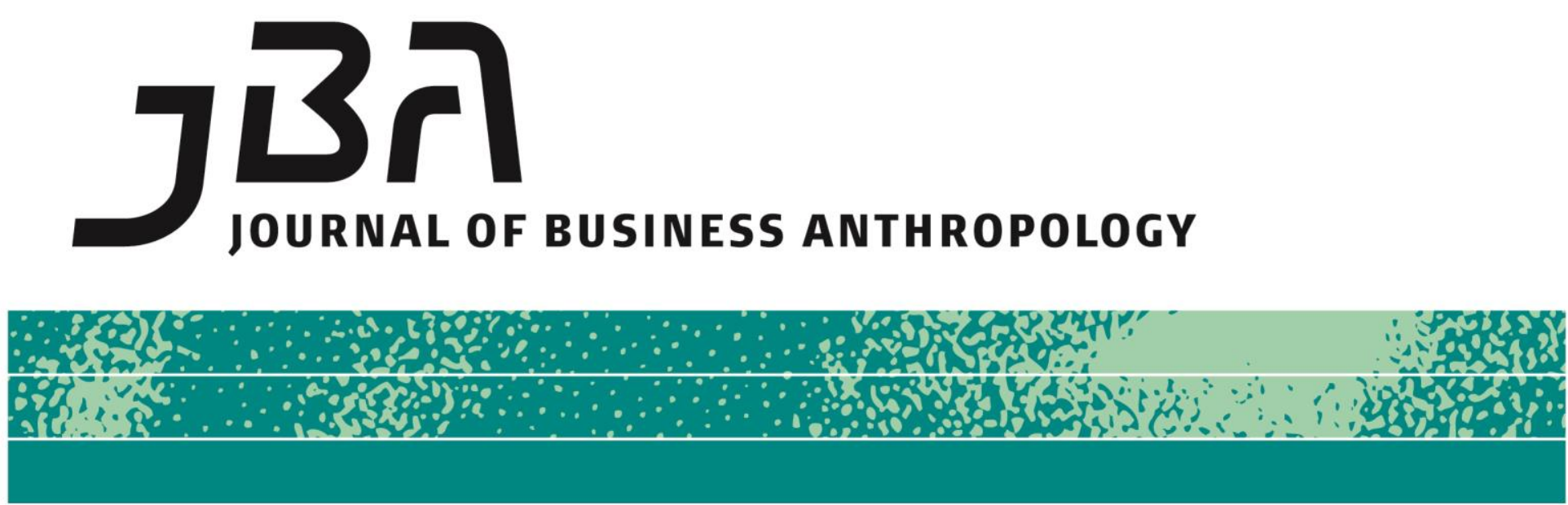

Essay

\title{
Digital divisions and the changing cultures of the music industries (or, the ironies of the artefact and invisibility)
}

Keith Negus, Goldsmiths, University of London

As has been extensively reported for a few years now, income from consumer sales of sound recordings has decreased. Sales of physical CDs are accelerating downwards. The digital artefact-the mp3 and its variants-has allowed the downloading, circulation and sharing of music in a manner that has raised questions about the social and economic value of recording. A recording is no longer a prized physical, numerically finite, collectable object; one visibly displayed in the store, under the arm when

Page 1 of 7

JBA 4(1): 151-157 Spring 2015

(C) The Author(s) 2015 ISSN 2245-4217

www.cbs.dk/jba walking down the street, or in the home. Somewhere, invisible, inside a machine, when not purchased as a download, it appears to be freely available-dripping from the cloud, swimming for survival in the stream. Yet, it is paid for through subscriptions, telephone and internet connection charges, the costs of computers, phones and iPads, speakers and headphones, and fees for electricity. The irony of "free" music is that it only appears free because the listener is not obviously making a transaction to labels or musicians-but, money is being made here.

The very ubiquity of digital music-the way it can be actively used, reused and circulated, or, perhaps more significantly, the way it can be 
skipped, passed by, ignored as part of the ambient drone of omnipresent mobile content-has impacted dramatically on listeners' judgements about the appropriate economic value of music (the price that should be paid for recordings), and its value within social life. The digital music file may or may not be an artefact (Sterne, 2006), but it just doesn't feel like an object containing the creative skills of musicians: a repository of the time and effort spent on composing, performing, and producing. It is not that tangible, fetishized, ritualistically revered phonographic object (Eisenberg, 1988), with album artwork, lyrics set out as poetry and explanatory liner notes-which is perhaps why vinyl is enjoying a resurgence.

Yet, these consumer perceptions of digital music's manifest characteristics are in stark contrast with the sentiments of musicians and pronouncements of music industries, presenting themselves as valiantly coping with this dramatic change in the perceived value of their creations, labours, and corporate systems. We have become familiar with the industry's widely circulated morality tale about theft and piracy on the digital oceans. And we know the counter claims that juxtapose powerful corporations and wealthy individual property-owning musicians against the sharing, caring, creative consumers making use of our collective human heritage. We are also more than vaguely aware that the digital music revolution has not led to an egalitarian and cooperative commons, but allowed ruthless, entrepreneurial organised crime networks and individuals (the infamous Kim Dotcom, for example) to become wealthy out of the creative labour of musicians and the altruistic industriousness of fans. Ethics are woven into commodity exchange, business relationships and copyright law.

At one time the ethics of popular music production appeared to be straightforward. Malevolent, manipulative, corrupt corporations were pitted against the creative imaginations and resourcefulness of fans and musicians. In popular journalism, criticism, and academic study, musicians and fans were routinely portrayed as united by a common affiliation-a community, subculture, or scene-and antagonistic to the demands and interests of record labels and the music business. Such a perspective could lead Simon Frith to write of musicians and audiences being engaged in a "continuous guerrilla war against the cultural power of capital and the state" (2007, p. 91)-a declaration intended to provoke debate as much as it might have indicated Frith's theoretical stance when it was first published in 1986. Despite the exaggerated military metaphor, this was more than a romantic conceit. Evidence had been accumulating for a number of years to support the claims for an antagonism and struggle that separated music corporations from musicians and their audiences (see Chapple and Garofalo, 1980). This claim also welded neatly with the new left cultural politics embraced by 1960s-70s sociology, and the populism of 1980s-90s cultural studies. 
But, the simple dichotomy of commerce (industry) versus art (musicians and audiences) was disrupted by legacies of a longer history, a contrasting narrative of conflicts between audiences and musicians. Hostilities between musicians and audiences were highlighted back in the 1950s by Howard Becker (1963) in his sociological studies of jazz musicians and their scorn for and fear of the "squares"; and articulated later in the early 1980s when Pink Floyd constructed The Wall across the front of the stage as a physical and symbolic barrier between "us" (the creative musicians) and "them" (the burdensome fans who have no understanding of the plight of the creative musician-a much parodied posture). These tensions were given a renewed impetus as bands such as Metallica berated their fans and went to court in order to stop Napster allowing the sharing of digital music via P2P networks. Musicians and record corporations found common cause in their campaigns against individual fans, resulting in prosecutions and court cases that "criminalised sharing" (David, 2010) and which now, just a few years later, look decidedly quaint in the corporate history of the popular music industry.

If, in retrospect, it was wishful thinking to assume fans and musicians united within a rock or hip-hop community or dance scene or punk subculture, so too it was misleading to believe that the so-called capitalist control of music was exerted monolithically and comprehensively. If that anthropomorphised entity capitalism (evoked incisively in Donald Barthelme's The Rise of Capitalism) is seeking to assert itself, there are a lot easier things to control and profit from than music and musicians. The logic of corporate dreams of media synergy (that 1980s buzzword) was disrupted by the unforeseen antagonisms and outright competition between formats (such as VHS and Betamax), and by the schisms between hardware manufacturers and software producers. Hence, the paradox of Philips making tape machines that allowed consumers to copy onto portable cassettes whilst their music division, PolyGram, was a member of the British Phonographic Industry (BPI) campaigning with the claim that "home taping is killing music."

We are currently witnessing a similar set of emerging competitive tensions within the business of music, between the traditional music industry and newer digital intermediaries of the IT industry. These conflicts within the cultures of capitalism entail contrasting accounts of how businesses should generate profits and then share that revenue; incompatible ethical principles and allied practices; and quite different approaches to the interplay of aesthetics, creativity, and capitalist exploitation. The revenue derived from sales of recordings to consumers may well have declined. Yet profits are being generated from music circulation by new digital intermediaries and data/ IT companies, notably iTunes and others selling downloads; YouTube providing a type of video mobile radio, whilst its parent Google "organises the world's information"; Spotify and others streaming access to music; games and 
media companies using recorded music. Much commentary over the past decade has bemoaned the way record labels were slow to respond to digitalisation. After years of uncertainty and procrastination, music labels and trade organisations were compelled to negotiate with these new platforms, agreeing a range of investment agreements, licensing deals, and royalty arrangements. Exact details are hard to ascertain due to the non-disclosure agreements favoured by the social media, data and computing industries. But anecdotal evidence about resulting divergent revenues suggests that music companies have reduced income available for reinvestment in new growth. Certainly, the trade organisations representing record labels and songwriters in the UK are concerned that companies such as YouTube/Google are not accurately reporting and passing on revenue for use of music on their platforms.

We are living through a critical moment in the relationship between what I'll call here the analogue and digital economy of music. The analogue economy is that pursued by what were once called record labels, now music companies. It is oriented towards production; emphasis is on locating repertoire and nurturing talent, recording and promoting that talent, and generating revenue from sales, performances, and rights usage of repertoire, with a demonstrable commitment to reinvest in new talent at the level of production. The digital economy is that pursued by the likes of Google, YouTube, and Spotify. It is more focused on content: on finding ways of circulating that content with the stated aim of "monetising content," by generating revenue from streaming, data collection and analytics, cloud storage, and by attracting advertisers to sites or pages containing sounds, images, data, and information. With various platforms allowing feedback and user exchange within forums, it entails placing musical content in various media as a means of generating revenue to support data production and content management, rather than investment in the production of repertoire and artists.

Some tentative and exploratory research, taken with commentary in trade sources, suggests that businesses able to mobilise data/analytics, and to generate advertising revenue from webpages in which sounds, words and images are the attraction, are gaining competitive advantage over a music industry that is premised on finding new music and working with songwriters, creators and producers. Yet,the notion that such "content" (a reductive abstraction) can in any simple way be "monetized" (an over-used opaque buzzword) is by no means straightforward. As John Lanchester has observed: "in the internet world, companies often seek growth first .... the strategy for monetising the product comes later. This is a sensationally good way of going broke" (2014, p. 186).

Content cannot simply be "monetised" without due attention, acknowledgment, and some type of relationship with the people who have created that content. This is perhaps why game manufacturers, and platforms allowing so-called user generated content (parodies, mash-ups, 
and blatant re-use of other creator's material), are reluctant, and perhaps have a vested interest in not asking where the content comes from. Music industry organisations representing songwriters and composers-such as the Performing Right Society (PRS) and British Academy of Composers Songwriters and Authors (BASCA)-are alarmed about the barriers that are impeding revenue collection and the inequitable splitting of the declared monies generated from platforms such as YouTube. As Vick Bain, CEO of BASCA, said to me when I spoke with her in November 2014: "the content creators are the foundation of the whole thing and if you cut them off, if you cut off the water supply, the whole thing falls over and all we'll be looking at is cat videos with no music'.

These emergent tensions in the digital economy, between production and consumption, between those whose profits are derived from producing music and those whose income is generated from exploiting the use of that music as "content," are perhaps part of a longer narrative about tensions between creativity and marketing, between producers and retailers. These conflicts are informed by widening disputes about "rights." Drawing from research on risk and the proliferation of intermediaries (Negus, 2014), and on a study of musicians, copying, and digitalisation with John Street and Adam Behr, ${ }^{1}$ one realizes clearly that there are three distinct but interrelated tensions.

First, as already noted, industry organisations, and musicians, have voiced concern that new digital intermediaries and IT companies are not recognizing and reporting the quantity of music being used on their services, and that rights revenue is not compensating for losses from sales. Musicians, particularly those without major star headline status, are finding it increasingly difficult to generate a return on even a modest investment in producing albums. Second, artists (and their advisors) have asserted the "right" to determine where their music is made available, highlighted by the case of Taylor Swift and others who have removed their music from streaming services. Third, new multiple rights contracts ("360 degree deals") have been constructed allowing music companies to claim "the right to participate" in third party agreements made by musicians with other companies: for instance, publishing, tour management and promotion, merchandising, or even related restaurant franchises (see Gervais, Marcus \& Kilgore, 2011).

These rights claims are underpinned by a series of ethical disputes about fairness and worth. The ethical questions concern the value of music, how this value should be recognised and rewarded, and how music should be circulated within digital networks that apparently allow the "free" flow of ideas, information, sounds and images. These ethical struggles underpin and inform arguments about how music should be distributed (sold, accessed via subscription, bundled with other services

\footnotetext{
1 http://www.create.ac.uk/research-programme/theme-4/wp4c3-digitisationand-the-politics-of-copying-in-popular-music-culture/
} 
and products, or offered "free"), and the type of payment and price for that form of distribution (a license, or royalty for a stream or download sale). These cultural tensions are between, on the one hand, a music industry firmly informed by an enduring romantic sensibility and investment in the musician as creative artist producing music that is expressive of individual, and collective identities; and, on the other, a social media and computing data industry valorising ruthless entrepreneurialism, obsessive corporate imaging, contractual secrecy, and the cult of the personality (Steve Jobs, Mark Zuckerberg) using music calculatedly as a "customer engagement tool" (Seabrook, 2014).

A large number of "customers" would seem to be "engaging" with digital music in a very different way to that of the conventional music fan imagined by the analogue music industry when it invests in new talent. The conventional music fan is assumed to be attentive to artistic nuances, loyal, and emotionally connected to a musician or band, willing to invest time, effort, and money in their musical preferences, valuing the creative outputs of their favourite artists by collecting and owning artefacts. The new music consumer is ambivalent about the plight of musicians and seeks access to their recordings rather than wishing to own them. The artistic impulse for coherent albums and artistic statements is irrelevant, far less interesting than forum discussion with other fans, or a hundred related pop-up tangential issues. The new music consumer assumes the ability to shuffle or dip into decontextualized tracks with no awareness of history and background, qualities, and knowledge usually conveyed with the physical package. Skipping is now fundamental to the new music consumer-almost 25 per cent of Spotify streams are skipped in the first five seconds (Lamere, 2014)-and part of the appeal of premium subscription services is the opportunity for unlimited skipping. There is a decisive difference between purchasing an individual song or album and paying a subscription to open up the digital floodgates. Surfing the sea of social and audio-visual content without drowning (whether it is awash with advertising or art, the flotsam and jetsam of "friends" or strangers) can only be navigated by constant skipping. Never mind the fact that unbundling might have led to the death of the album, skipping is fast, accelerating the death of the three-minute pop song that is listened to in its entirely.

Yet, paradoxically, in the last two years, vinyl albums and singles have been dramatically increasing in popularity, with sales growing 78 per cent in the UK during 2013, 52 per cent in the USA during 2014, and overall sales being at an eighteen year high, as labels, stores and vinylonly club nights sustain themselves by attracting a small niche of devoted music fans (Gibson, 2015). This is not a nostalgic market for those who grew up with the album, but has great appeal for the more active fans of music and a newer generation of musicians (as will be apparent if you simply spend time in the new wave of vinyl record stores). Vinyl embodies and signifies a tangible collection of musical values. Sales may 
be statistically insignificant in economic terms, but the investments of listeners and musicians in vinyl may be of great cultural and symbolic importance, as this history is played out. As record players collide with smartphones, now may be an opportune moment for anthropologists to turn their attention to the cultures of production and consumption through which popular music is circulating.

\section{References}

Chapple, Steve and Garofalo, Reebee Rock'n'Roll is Here to Pay, Nelson Hall, Chicago, 1980.

David, Matthew Peer to Peer and the Music Industry: The Criminalisation of Sharing, Sage, London, 2010.

Eisenberg, Evan The Recording Angel: Music, Records and Culture From Aristotle to Zappa, Picador, London, 1988.

Frith, Simon "Art Vs Technology: The Strange Case of Popular Music" in Taking Popular Music Seriously, Selected Essays, Ashgate, Farnham, 2007.

Gervais, Daniel, Kent, Marcus and Lauren Kilgore "The Rise of 360 Deals in the Music Industry," Landslide Vol. 3 No. 4, April 2011.

Gibson, Megan "Here's Why Music Lovers are Turning to Vinyl and Dropping Digital," Time Magazine 13 January 2015.

http://time.com/3663568/vinyl-sales-increase/

Lamere, Paul “The Skip," Music Machinery, 2014.

http://musicmachinery.com/2014/05/02/the-skip/

Lanchester, John How to Speak Money, Faber and Faber, London, 2014.

Negus, Keith "Recordings, Rights and Risks: Intermediaries and the Changing Music Industries," Civilisations: Revue Internationale

D’Anthropologie et de Sciences Humaines, No. 13, 2014, pp. 113-136.

Seabrook, John "Revenue Streams," The New Yorker, 24 November 2014. http://www.newyorker.com/magazine/2014/11/24/revenue-streams

Sterne, Jonathan "The mp3 as cultural artefact," New Media and Society, Vol. 8 No. 5, 2006, pp. 825-842.

Keith Negus is Professor of Musicology at Goldsmiths, University of London. His books include Producing Pop (1992), Popular Music in Theory (1996), Music Genres and Corporate Cultures (1999) and Bob Dylan (2008). He has published articles on various topics including creativity, musicians on television, globalization, narrative and the popular song, music genres, and cultural intermediaries. He is currently researching 'Digitisation and the Politics of Copying in Popular Music Culture' with John Street and Adam Behr. He is also working with Pete Astor, researching and writing about songwriting, as well as creating songs as The Fairlight Myth. He may be reached at K.Negus@gold.ac.uk. 